\title{
Article
}

\section{An investigation of the relationship between thermal imaging and digital thermometer}

Erande, Renuka, Dey, Maria Paola, Richards, James and Selfe, James

Available at http://clok.uclan.ac.uk/12818/

Erande, Renuka, Dey, Maria Paola, Richards, James ORCID: 0000-0002-40043115 and Selfe, James (2015) An investigation of the relationship between thermal imaging and digital thermometer. Physiotherapy Practice and Research, 37 (1). pp. 41-47. ISSN 2213-0683

It is advisable to refer to the publisher's version if you intend to cite from the work. http://dx.doi.org/10.3233/PPR-150067

For more information about UCLan's research in this area go to http://www.uclan.ac.uk/researchgroups/ and search for < name of research Group>.

For information about Research generally at UCLan please go to http://www.uclan.ac.uk/research/

All outputs in CLoK are protected by Intellectual Property Rights law, including Copyright law. Copyright, IPR and Moral Rights for the works on this site are retained by the individual authors and/or other copyright owners. Terms and conditions for use of this material are defined in the policies page.

\section{CLoK}

Central Lancashire online Knowledge www.clok.uclan.ac.uk

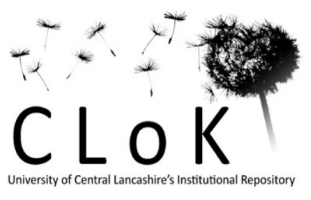




\title{
AN INVESTIGATION OF THE RELATIONSHIP BETWEEN THERMAL IMAGING AND DIGITAL THERMOMETER TESTING AT THE KNEE
}

Short Title: Relationship between Thermal Imaging and Digital Thermometer testing at the knee

\author{
Renuka Erande $^{1,3}$, Paola Dey ${ }^{2}$, Jim Richards ${ }^{1}$, James Selfe ${ }^{1}$
}

${ }^{1}$ School of Sports Tourism and the Outdoors, University of Central Lancashire, PR1 2HE, United Kingdom

${ }^{2}$ School of Postgraduate Medical \& Dental Education, University of Central Lancashire, PR1 2HE, United Kingdom

${ }^{3}$ University College London Hospitals NHS Foundation Trust, WC1E 6EB, United Kingdom

Correspondence to:

Renuka Erande

BB121, Brook Building, School of Sports Tourism and the Outdoors, University of Central Lancashire, PR1 2HE, United Kingdom

Telephone: +44 1772894571

Fax: +44 1772892914

Email: $\underline{\text { RErande@uclan.ac.uk }}$

Short title: The agreement between Thermal Imaging and a Digital Thermometer 


\begin{abstract}
BACKGROUND: A number of research papers and theoretical clinical models summarising how temperature of the skin over the knee may be altered according to different pathological processes have been published. Thermal imaging (TI) is generally regarded as the 'Gold' or 'reference' standard for measuring skin temperature, however this technology is not widely accessible to most musculoskeletal physiotherapists working in clinical environments. This is largely due to the time required for analysis of the thermal images and high cost of the equipment. A digital thermometer (DT) is portable with a convenient display of results which could offer an inexpensive substitute.
\end{abstract}

AIM: This study determined interchangeability between thermal imaging and a digital thermometer, using Bland-Altman limits of agreement, to determine skin temperature differences between right and left knees.

METHOD: 71 healthy participants in the age group of 8 to 40 participated in the study. Data were collected in two phases. The first phase was as part of a public engagement event at the Lancashire Science Festival where school children were invited to learn about science. The second phase of data collection took place as part of a $\mathrm{PhD}$ study where staff and students at the university were recruited via electronic advert and posters displayed around the campus. All subjects were free from lower back or lower limb problems and had not had any previous lower limb surgery.

RESULTS: Matched paired t tests showed no significant difference between temperature difference between right and left using DT and TI $(\mathrm{t}=1.41, \mathrm{df}=69, \mathrm{P}=0.08)$. The DT and TI were interchangeable to measure knee skin temperature difference with a limit of agreement of -0.64 and 0.75 ; this limit of agreement is acceptable based on previous literature where skin temperature differences between affected and non-affected knees are equal to or greater than $1^{\circ} \mathrm{C}$.

CONCLUSION: This study concludes that an inexpensive handheld digital thermometer shows acceptable agreement with a thermal imaging camera. Clinically a handheld digital thermometer has the potential to play an important role in the localized assessment of skin temperature in physiotherapy and can offer an inexpensive substitute to thermal imaging; due to the massive difference in cost it is worth considering the adoption of digital thermometry in routine musculoskeletal physiotherapy practice.

Key words: knee skin temperature, Infrared Thermal Imaging, Digital Thermometer, relationship, agreement 


\section{Introduction}

Physiotherapists have traditionally manually assessed raised skin temperature to evaluate the presence of inflammation in underlying tissues. Within podiatry instrumented skin temperature monitoring has become established as a valuable technique in detecting sites at risk of ulceration in patients with neuropathy [1] and inexpensive digital readout thermometers have become part of the podiatrists clinical assessment toolkit for assessing inflammation. It is less common to evaluate vascular or ischaemic disorders by assessing decreased skin temperature within orthopaedic and musculoskeletal practice. However it has been reported that reduced dorsal hand skin temperature occurs in patients with severe upper extremity musculoskeletal disorders which may reflect an underlying dysfunctional sympathetic nervous system [2]. In the lower limb there is a body of evidence that suggests some patellofemoral pain (PFP) may also be attributable to vascular disturbance and ischaemia [3] and some argue that biomechanics alone cannot fully account for pain in all patients with PFP [4]. Sandow and Goodfellow (1985) observed in a sample of 54 adolescent girls that 9 out of 54 (16.7\%) had pain that was aggravated by cold weather [5]. Coughlan et al (1987) examined a group of patients with chronic knee pain who had associated vasomotor disturbance which was clinically detectable by the presence of cold affected limbs. The link between pain and low skin temperature was confirmed by return to normal limb temperature symmetry in patients whose pain completely or almost resolved. In other patients with persisting pain the thermal asymmetry persisted [6]. In a study of outcome in a group of PFP patients with cold knees it was found that these patients experienced greater initial pain levels and were un-responsive to a standard exercise based physiotherapy treatment programme [7]. It has also been observed that in half of PFP patients an accelerated bone remodelling in the knee joint takes place which may be due to a dysfunctioning sympathetic nervous system which could be a cause of intermittent ischemia and pain [8]. More recently Selfe et al (2010) investigated cold knees in PFP using a thermal imaging camera [9]. They reported a statistically significant difference between the cold and not cold groups in the mean baseline knee skin temperature $\left(-1.2^{\circ} \mathrm{C}, \mathrm{p}=0.006 ; 95 \%\right.$ confidence interval $-2.0^{\circ} \mathrm{C}$ to $-0.4^{\circ} \mathrm{C}$ ). The patients with cold knees had lower levels of activity and function. Thermal imaging is a non-invasive and non-radiating tool which provides sensitive and accurate images of local skin temperature [10]. However, two of the main drawbacks of thermal imaging applications for clinical practice are the financial implications as high quality thermal imaging cameras have a significant cost and the time required for analysis of the thermal image. A digital skin temperature thermometer is portable, fitting into a pocket and could offer an inexpensive substitute to thermal imaging. Digital skin thermometers also have the advantage that they are capable of producing instant objective data useful for 'real time' clinical decision making.

This study compared the agreement in skin temperature readings at the knee as measured by a thermal imaging camera and a hand held low cost digital thermometer. Both thermal imaging cameras and digital skin thermometers use thermal detectors which have a sensitivity in a similar wave band to 
measure naturally emitted infrared radiation from the skin surface. As the same sensing principle is employed, the results of a comparison between these two instruments should be similar. The objective was therefore to determine whether sufficient agreement exists between the two types of temperature measurement equipment, to allow the inexpensive digital thermometer to be used clinically as a replacement for the thermal imaging camera to determine skin temperature difference between knees. Thermal imaging was used as a reference standard as it has been shown to distinguish temperature changes as subtle as $0.02^{\circ} \mathrm{C}$ [11]. However we acknowledge the limitation in this approach as there have been few clinical thermal imaging studies investigating the value for minimum clinically important differences in skin temperature asymmetries of the anterior knee [12]. For this study, given that a difference of $1^{\circ} \mathrm{C}$ or more between knees is considered by some as clinically meaningful [13], we considered that limits of agreement of less than $+/-1^{\circ} \mathrm{C}$ would suggest that thermal imaging could be replaced by a digital thermometer for detecting meaningful differences in skin temperature in clinical practice.

\section{Methods}

Data were collected in two phases. The first phase was as part of a public engagement event at the Lancashire Science Festival where school children were invited to learn about science. We had a stand demonstrating the use of thermal imaging in musculoskeletal conditions. Children who came to interact with our stand were asked if they would like to take part in a 'real' experiment, and where participants were under 16 years of age verbal assent was additionally taken from their accompanying guardian. If they agreed a thermal image and digital temperature measurement were recorded and they were shown their own knee thermal image. The second phase of data collection took place as part of a PhD study where staff and students at the university were recruited via electronic advert and posters displayed around the campus. After written consent was obtained, participants underwent a number of tests of the knee including those reported here. All participants enrolled in both phase 1 and phase 2 were free from lower back or lower limb problems and had not had any previous lower limb surgery. Prior to data collection in either phase, appropriate institutional ethical approval by the University of Central Lancashire was obtained and studies were performed in accordance with the Declaration of Helsinki [14].

\subsection{Materials}

Knee skin temperature was assessed using a FLIR A325 thermal imaging camera (TI) (ThermoVision A325 Flir Systems, Danderyd, Sweden) and an IR 21 B digital thermometer (RDSM nv, Hasselt, Belgium). The thermal imaging camera used in this study has a thermal sensitivity of $<0.07$ at $+30^{\circ}$ [11]. The digital thermometer met the accuracy requirement in ASTM E1965-98 [15] and the EC directive 93/42/EEC. The type of temperature assessment (TI or DT) was standardized such that thermal imaging was always carried out first followed by the digital thermometer. This was to prevent 
the influence of DT probe contact on knee skin temperature. The digital thermometer was designed for use in foot temperature measurement. The temperature sensing element does not touch the skin however the rim of the thermometer is in contact with the skin. Participants were given 15 minutes to acclimatise to the room temperature, allowing their skin temperature to stabilise [16]. Both tests were performed on each knee. In addition both tests were carried out by the same researcher who was a qualified physiotherapist trained appropriately in using the 2 tools.

\subsection{Thermal Imaging}

Participants were seated with hips flexed to $90^{\circ}$. The thermal imaging camera was mounted on a tripod, the height of which was determined by the camera angle, standardized to $90^{\circ}$. Thermally inert markers were placed at specific anatomic locations, defining an area over the anterior knee referred to as the region of interest (ROI) [17]. The four markers were placed on the widest medial and lateral points; longest upper and lower border of patella which were then identified on the computer screen and later manually joined together using the polygon tool (Thermacam Researcher 2.8 software, Flir systems, Sweden) to define the region of interest. Mean surface skin temperature of the ROI was calculated for each image.

\subsection{Digital Thermometer}

Knee skin surface temperature was recorded using a digital thermometer at the centre of patella. An average of 3 readings was taken at the centre of patella on both knees.

\subsection{Statistical methods}

All data from the thermal imaging and digital thermometry of each knee was entered into SPSS 17.0.1 for Windows (SPSS Inc., Chicago, IL) and Microsoft Office Excel 2007 (Microsoft Corporation, Redmond, WA) for analyses. Paired t tests were conducted (a) between the temperature at right and left knee using digital thermometer (b) between the temperature at right and left knee using thermal imaging (c) and on side to side temperature differences using thermal imaging and digital thermometer to determine if there was a significant difference. Pearson product-moment correlation coefficients were used to assess the strength of the relationships between the TI and DT. The alpha level for statistical significance was set at $\mathrm{P}<0.05$. Bland and Altman plots with $95 \%$ limits of agreement [18] were used to assess the agreement between the skin temperatures measured using thermal imaging and digital thermometer.

\section{Results}

71 healthy participants in total (34 females, 37 males; mean age 19.17 years \pm SD 10.04) participated in this study. Mean room temperature was $22.7^{\circ} \mathrm{C}\left(\mathrm{SD} 0.5^{\circ} \mathrm{C}\right.$, range $\left.22.0^{\circ} \mathrm{C}-23.6^{\circ} \mathrm{C}\right)$. The mean knee skin temperature using thermal imaging was $31.48^{\circ} \mathrm{C}\left(\mathrm{SD} 1.80^{\circ} \mathrm{C}\right)$ for the right knee and $31.48^{\circ} \mathrm{C}$ (SD $1.83^{\circ} \mathrm{C}$ ) for the left knee. The mean knee skin temperature using the digital thermometer was $30.22^{\circ} \mathrm{C}$ $\left(\mathrm{SD} 1.89^{\circ} \mathrm{C}\right.$ ) for the right knee and $30.15^{\circ} \mathrm{C}\left(\mathrm{SD} 1.88^{\circ} \mathrm{C}\right)$ for the left knee. The mean skin temperature difference between right and left knee using thermal imaging was $0.01^{\circ} \mathrm{C}\left(\mathrm{SD} 0.60^{\circ} \mathrm{C}\right)$ and using the 
digital thermometer was $0.06^{\circ} \mathrm{C}\left(\mathrm{SD} 0.69^{\circ} \mathrm{C}\right)$. A paired t test showed no significant difference between the skin temperature of the right and left knee using thermal imaging $(t=0.02, d f=69$, $\mathrm{P}=0.49)$ or with the digital thermometer $(\mathrm{t}=0.74, \mathrm{df}=69, \mathrm{P}=0.23)$. A paired $\mathrm{t}$ test conducted on differences between right and left knee temperature measurements using thermal imaging and the digital thermometer showed no significant difference $(\mathrm{t}=1.41, \mathrm{df}=69, \mathrm{P}=0.08)$. There was a significant correlation between side to side temperature difference measured using the 2 instruments $(\mathrm{R}=0.86, \mathrm{P}=0.09)$.

A box-and-whisker plot showing the distribution of temperature at right and left knee using TI and DT is shown in figure 1. The plot shows higher medians for thermal imaging readings at right and left knee demonstrating higher temperature readings as compared to the digital thermometer readings at both knees.

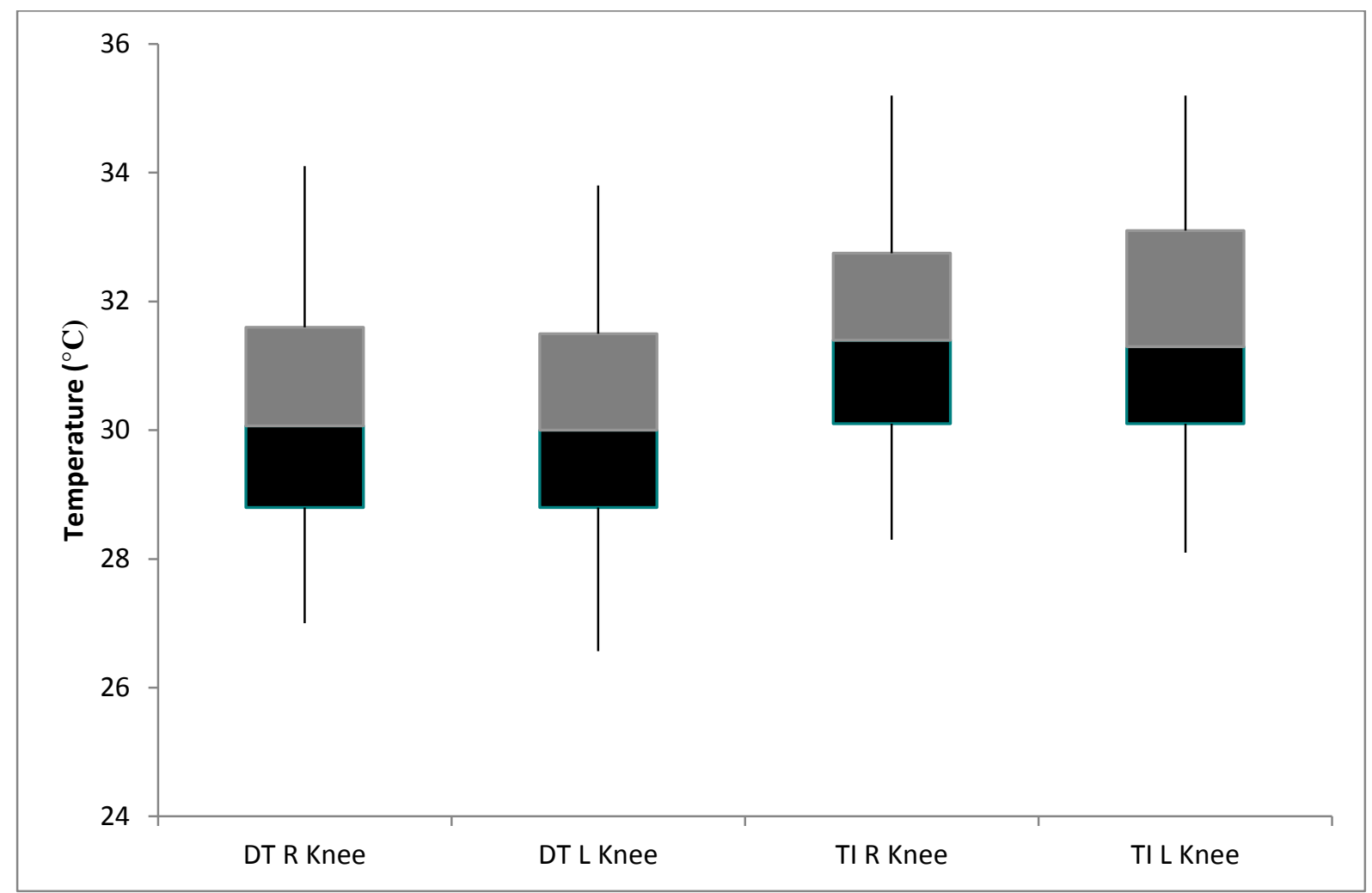

Figure 1: Box and whisker plot showing the distribution of temperature in Celcius at right and left knee using Digital Thermometer (DT) and Thermal Imaging (TI)

To determine the interchangeability of the 2 temperature measuring instruments, Bland and Altman (BA) limits of agreement methodology were applied to data. The Bland and Altman results are plotted in Figures 2 and 3. The mean bias was 0.06 . The 95\% limits of agreement were -0.64 and 0.75 . The 
95\% confidence interval for the lower limits of agreement was -0.78 to -0.49 and for the upper limits of agreement was 0.61 to 0.89 .

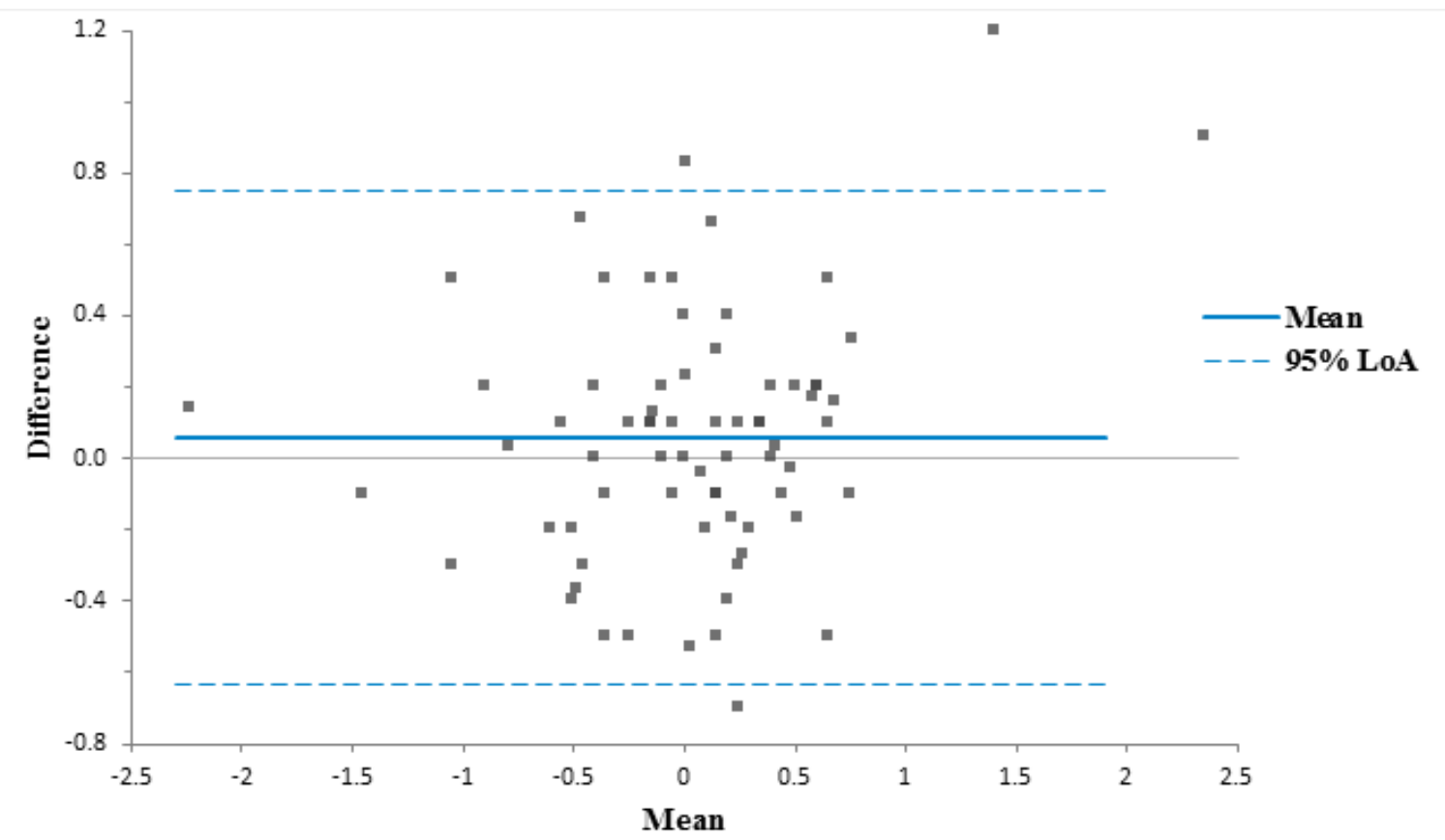

X Axis: Mean of temperature difference between right and left knee measured using Thermal Imaging and Digital Thermometer

Y Axis: Difference of temperature difference between right and left knee measured using Thermal Imaging and Digital Thermometer

Figure 2: Comparison of differences in temperature differences in Celcius between right and left knee using Thermal Imaging (reference standard) and Digital Thermometer 


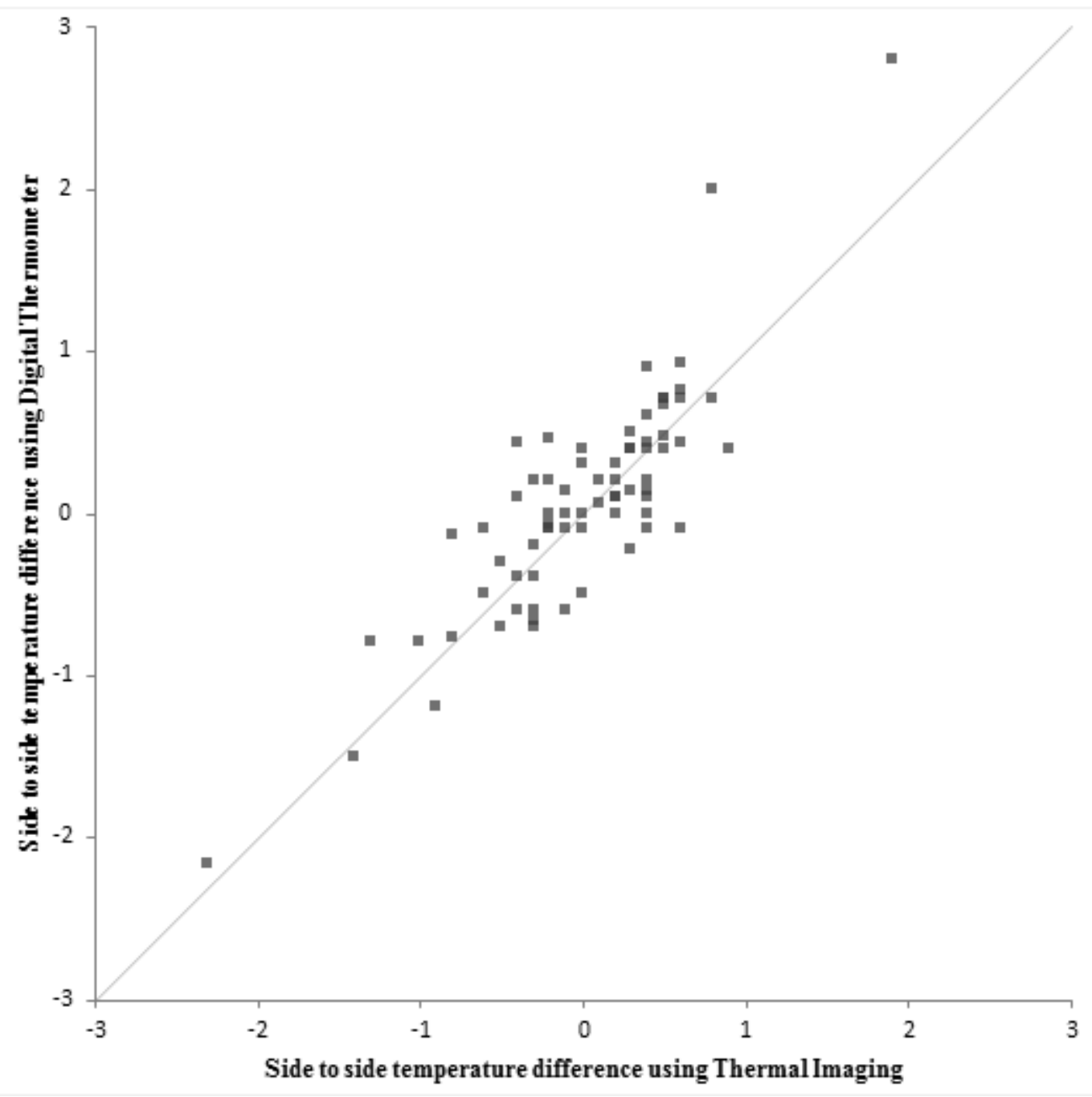

Figure 3: Comparison of side to side temperature differences in Celcius measured with Digital Thermometer and Thermal Imaging with line of equality

\section{Discussion}

The aim of this study was to determine if agreement exists between the two temperature measuring instruments to determine any temperature difference between left and right knee. The mean difference of side-to side temperature difference using TI and DT was 0.06 . The mean difference between right and left knee using digital thermometer (0.063) was higher than thermal imaging (0.007). Despite this, the limits of agreement (-0.64 and 0.75 ) are small enough and within \pm 1 based on the criterion for a clinically important difference for this study, for us to be confident that the digital thermometer can be used in place of thermal imaging to determine knee temperature differences for clinical purposes.

All skin temperature measurements recorded in this study fall within the range of knee skin temperature reported in a recently published large scale review of knee temperature measurements [19]. Interestingly in contrast to this review we consistently found slightly lower digital thermometer 
readings compared to thermal imaging. This may be due to the nature of our experiment using the same individuals where it is possible that participants had not acclimatised fully to the ambient temperature and so their knees cooled slightly between the measurements even though both measurements were performed within a short time frame ( $<1$ minute) of each other on each knee. The results from this study show that the digital thermometer consistently measures skin temperature at the anterior knee lower than thermal imaging by an average of $1.3^{\circ} \mathrm{C}$. There was a significant difference between the absolute temperatures of thermal imaging and digital thermometer and so the absolute temperature values between the tools are not interchangeable.

It is important to view these results in light of potential clinical applications of objective temperature measurements within musculoskeletal physiotherapy; temperature difference comparisons between different anatomical sites or on the same site over a period of time could be important indicators for initial diagnosis and in the evaluation of treatment outcomes in clinical and research settings.

\subsection{Diagnostic aid}

It is key to interpreting potentially clinically important data to know that the skin temperature of a healthy knee is normally lower than that of contiguous skin. Menard and Paquette (1980) demonstrated that skin temperature at the knee was $1.23^{\circ} \mathrm{C}$ less than the temperature at tibia in normal participants [20]. If the difference is exaggerated, so that the knee becomes excessively cold, this may be an indication that there is a sympathetic component to the patient's condition. Sympathetically maintained pain is characterised by low temperature over the total knee [19]. In contrast in patients with inflamed knees the temperature at the knee is reported to be higher by an average of $0.57^{\circ} \mathrm{C}$ as compared to the tibia [20] and it is suggested that in inflammatory arthritis, patients present with diffuse heat over the knee with a hot patella [19]. Patellar skin surface temperature has been found to demonstrate an interesting interrelationship with structural knee OA damage as measured by the Kellgren-Lawrence scale, where higher temperatures were found in knees with greater structural damage [21]. In PFP a clinical model summarising how temperature may be altered according to different pathological processes has previously been published [22].

\subsection{Outcome monitoring}

Regular monitoring of temperature and identifying temperature differences overtime could help in monitoring appropriate treatment strategies related to either the ischaemic causes of pain or inflammatory causes of pain. In patients with chronic knee pain with cold knees, a return to normal limb temperature symmetry was demonstrated in patients whose pain completely or almost resolved [6], unfortunately no details of the successful therapeutic procedures that restored temperature and function to normal are given. It has been reported that patients with patellofemoral pain with cold knees had worse outcomes and showed less improvement in response to an exercise based approach to physiotherapy than PFP patients with normal temperature knees [7]. Therefore using skin temperature measurement may assist musculoskeletal clinicians in formulating alternative treatment strategies 
[23]. For example in an ABA design single case experiment using acupuncture in a PFP patient with an excessively cold knee it was demonstrated that during the course of treatment as skin temperature increased, pain decreased and function improved [24].

A limitation of this study is the generalizability of the results to other body parts as the data were collected only at the knee. Also data in this study was collected only in healthy participants and the experiment should be repeated in disease groups as these display differing thermal profiles [18].

\section{Conclusion}

This study concludes that an inexpensive handheld digital thermometer shows good agreement with a thermal imaging camera in measuring side to side temperature difference. The absolute temperature readings measured by the two tools are not interchangeable. Clinically a digital thermometer has the potential to play an important role in the localized assessment of skin temperature and can offer an inexpensive substitute to thermal imaging. Due to the massive difference in the cost between the 2 instruments it is worth considering the adoption of digital thermometry in routine musculoskeletal physiotherapy practice.

\section{Acknowledgements}

This work was supported by the host institution of the author's; no external grant income supported this work. None of the authors have any professional or financial affiliations with any of the equipment suppliers for this work or any other third party, which may have caused intentional or otherwise bias. 


\section{References}

[1] Lavery LA, Armstrong DG. Temperature Monitoring to Assess, Predict, and Prevent Diabetic Foot Complications. Current Diabetes Reports 2007;7:416-419.

[2] Gold JE, Cherniack M, Hanlon A, Dennerlein JT, Dropkin J. Skin temperature in the dorsal hand of office workers and severity of upper extremity musculoskeletal disorders. Int Arch Occup Environ Health. 2009;82:1281-92.

[3] Sanchis-Alfonso V, Rosello-Sastre, E. Anterior knee pain in the young patient-what causes the pain? "Neural model", Acta Orthop Scand 2003;74:697-703.

[4] Dye S, Staubli HU, Biedert RM, Vaupel GL. The mosaic of pathophysiology causing patellofemoral pain: Therapeutic implications. Operative Techniques in Sports Medicine. 1999;7:4654.

[5] Sandow MJ, Goodfellow JW. The natural history of anterior knee pain in adolescents. J Bone Jt Surg (Br) 1985;67:36 -38.

[6] Coughlan RJ, Hazleman BL, Thomas DP, Sattelle L, Crisp AJ, Jenner JR, Dandy DJ. Algodystrophy: a common unrecognised cause of chronic knee pain. British Journal of Rheumatology. 1987; 26:270-274.

[7] Selfe J, Harper L, Pedersen I, Breen-Turner J, Waring J, Stevens D. Cold legs: a potential indicator of negative outcome in rehabilitation of patients with syndrome. The Knee. 2003;10:139143.

[8] Naslund J, Walden M, Lindberg LG. Decreased pulsatile blood flow in the patella in patellofemoral pain syndrome, American Journal of Sports Medicine 2007;35:1668-1673.

[9] Selfe J, Sutton C, Hardaker NJ, Greenhalgh S, Karki A, Dey P. Patellofemoral pain and cold knees: A possible association in women. The Knee. 2010;17:319-323.

[10] Ring EFJ; Ammer K. Infrared Thermal Imaging in Medicine. Physiological Measurement. 2012; 33:33-46.

[11] Flir. Thermal imaging cameras for Research and Development. 2012; http://www.flir.com/uploadedFiles/Thermography/MMC/Brochures/T820147/T820147_EN.pdf (accessed 3 October 2012)

[12] Selfe J, Whittaker J, Hardaker N. A narrative literature review identifying the minimum clinically important difference for skin temperature asymmetry at the knee. Thermology International. 2008;18:51-54.

[13] Ring FJ, Ammer K. Thermal Imaging in Disease of the Skeletal and Neuromuscular Systems. In:

Diakides M, Bronzino JD, Peterson DR, editors. Medical Infrared Imaging Principles and Practices. Florida: CRC Press; 2012. p. 25-9.

[14] World Medical Association. Declaration of Helsinki. 2002. 
http://www.wma.net/e/ethicsunit/helsinki.htm.

[15] American Society for Testing and Material (ASTM). Standard specification for infrared thermometers for intermittent determination of patient temperature. ASTM Designation- E 1965-98. 1998;1-17.

[16] Ammer K, Ring EFG. The Thermal Image in Medicine and Biology. Wien: Uhlen-Verlag. 1995; 82-187.

[17] Selfe J, Hardaker N, Thewlis D, Karki A. An Accurate and Reliable Method of Thermal Data Analysis in Thermal Imaging of the Anterior Knee for use in Cryotherapy Research. Archives of Physical Medicine and Rehailitation. 2006;87;1630-1635.

[18] Bland JM, Altman DG. Statistical methods for assessing agreement between two methods of clinical measurement. Lancet. 1986;307-310.

[19] Ammer K. Temperature of the human knee - a review. Thermology International. 2012; 22:137151.

[20] Menard HA, Paquette D. Skin Temperature of the knee: an unrecognized physical sign of inflammatory disease of the knee. Canadian Medical Association Journal. 1980;122:439-440.

[21] Denoble AE, Hall N, Pieper CF, Kraus VB. Patellar Skin Surface Temperature by Thermography Reflects Knee Osteoarthritis Severity. Clinical Medicine Insights: Arthritis and Musculoskeletal Disorders. 2010;3:69-75.

[22] Selfe J, Karki A, Stevens D. A review of the role of circulatory deficit in the genesis of patellofemoral pain. Physical Therapy Reviews. 2002;7:169-172.

[23] Selfe J. Patellofemoral Pain: Myths; Truths; Future Directions. Physiotherapy Ireland. 31;2:1618

[24] Tootill I, Hayes C, Hardaker N, Selfe J. Acupuncture for the treatment of Patellofemoral Pain: A Single Case Experiment with an ABA design. Journal of the Acupuncture Association of the CSP. 2011;3:99-103. 